\title{
Современная болгарская архитектура (1989-2020): состояние, проблемы, тенденции
}

\author{
Атанас Ковачев, Лесотехнический университет, София, Болгария \\ Мария Давчева, Болгарская академия наук, София, Болгария
}

Картина современной болгарской архитектуры периода (1989-2020) годов не только динамично меняется, но и точно отражает кардинально меняющуюся внутреннюю ситуацию, определяемую взаимосвязанными политическими и социально-экономическими условиями в этот конкретный исторический период нашей страны. Авторами предпринята попытка проследить в определенных границах метаморфозы архитектурных проектов и реализаций, а также генезис новых типов зданий с целью определения предпочтений при их выборе.

Modern Bulgarian Architecture (1989-2020): State, Problems, Trends

A. Kovachev, University of Forestry, Sofia, Bulgaria

M.Davcheva, BAS, Sofia, Bulgaria

The image of contemporary Bulgarian architecture from the period $1989-2020$ is a dynamically changing picture, but also an accurate reflection of the equally rapidly changing local economic framework, defined by the interrelated political and socio-economic parameters in this particular historical period for our country. In the present material, without claiming to be exhaustive, but within specific limits, has been made an attempt to trace the metamorphoses in architectural projects and realizations, as well as the genesis of new types of buildings, to mark the reasons for the dropout of others.

\section{Переходный период}

Процессы, идущие в Болгарии последние тридцать лет, вызванные политическими, экономическими, а затем социальными и культурными изменениями - тем, что называется перестройкой, - разнообразны и противоречивы. Этап, называемый «переходным периодом» (1989-2019), - следствие общего изменения политического режима, обусловленного исчерпанием предыдущих моделей взаимодействия и переходом к демократии и рыночной экономике.

После падения в ноябре 1989 года тоталитарного режима последовали многократные смены (на сегодняшний день более тридцати раз) политико-административного аппарата с последовательным чередованием политических партий, оппозиции и вновь созданной контроппозиции. Соответственно и вера в быструю европеизацию Болгарии быстро уменьшалась.

В 2007 году Болгария вступила в Евросоюз. Находясь под жёстким внешним мониторингом, целями которого являются прозрачность, подотчётность и ответственность в финансовых отношениях, Болгария демонстрирует самый устойчивый процесс европеизации в своей истории, который, хотя и косвенно, определяет единые и строгие правила в экономике, в строительстве и других важнейших жизненных процессах. Мировой финансовый кризис уже во второй раз (после 1997 года) испытал общие экономические и политические рамки существования Болгарии как государства, а также устойчивость болгар.

Это сказалось не только на строительстве и архитектуре - быстро и устойчиво развивающихся секторах болгарской экономики, но также поставило много вопросов о плановом развитии городской среды и обо всех составляющих этого процесса, гарантирующих высокий уровень жизни, включая работу, спорт, развлечения и др.

После прекращения (начиная с 1989 года) эксплуатации крупных объектов национального значения и начала процессов реституции (возвращение бывшим владельцам собственности, национализированной после 1944 года) появились новые виды частной деятельности, а рыночная экономика заменила плановую со всеми вытекающими отсюда отрицательными и положительными последствиями. К сожалению, в Болгарии не было законов, с помощью которых можно было бы управлять частной предпринимательской деятельностью или хотя бы как-то регулировать эти процессы, болгарская экономика оказалась не готова принять продукты экономической деятельности, основанной на частной собственности.

Как и бывает в переходные периоды, первыми в болгарское общество начали проникать новые философские и культурные веяния, «новое искусство» - произведения кино, театра, изобразительного и прикладного искусства, архитектуры и т.д. Вследствие этого претерпели глубокие изменения и идеи «нового искусства» и само отношение к нему [1].

Снятие ограничений, существовавших до 1989 года, расширение свободы выражения мнений и неограниченный доступ к информации превратили в конце XX века болгарскую архитектурную сцену в настоящую экспериментальную лабораторию. Одновременно и одинаково успешно несколько поколений архитекторов создали первые здания различного назначения в современной Болгарии.

Известные архитекторы второй половины XX века, такие как Георгий Стоилов, Лозан Лозанов, Богдан Томалевский, Владимир Роменский, Атанас Агура, оставили свой индивидуальный, хорошо узнаваемый отпечаток в болгарской архитектуре переходного периода. Вполне естественно, что благодаря своему авторитету и опыту они стали в этот период авторами первых крупных болгарских проектов, участниками международных конкурсов. То было время, когда архитектурные идеи превосходили возможности их реализации. Этому испытанию 
подверглись как сами авторы и их проекты, так и терпимость общества и его способность воспринимать и усваивать новое.

Проекты и реализации представителей первой волны нового поколения - архитектурных мастерских Жеко Тилева, Танко Серафимова, Владимира Михова, Атанаса Панова, Иво Петрова, Иво Панталеева и других - демонстрируют видимое восходящее развитие. На идеи этих архитектурных бюро большое влияние оказывает современная западная архитектура, и в большинстве случаев именно их здания делают узнаваемой окружающую среду, раскрывая её идентичность, зачастую становясь символом места или функции, которая в них реализуется. Важным фактором в стабильном развитии этого архитектурного сообщества является не только бесспорный талант их ведущих архитекторов, руководителей мастерских, но и выработанная с течением времени преемственность.

Представителями второй волны являются молодые, но уже известные за пределами Болгарии архитектурные студии, такие как «ASA», «Starh», «I/0», «Aedes», «A\&A Architects», «10 architects», «Planing»,» IP architects», «17,5-С» и другие

Свой вклад в формирование облика современной болгарской архитектуры внесли и специализированные предпринимательские компании, создавшие подразделения для выполнения строительных и проектных работ, управления проектами, недвижимо-

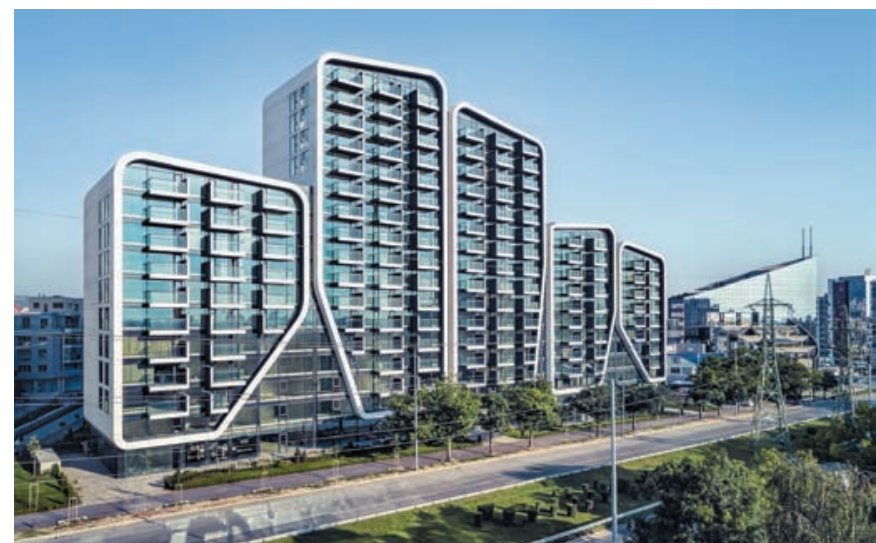

Puc. 1. АЗ (Апартаменты с развитой архитектурой). София. STARH. 2015-2017 годы (источник: STARH'2019)

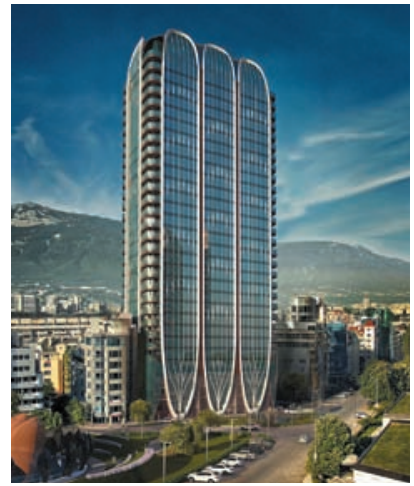

Рис. 2. Жилая башня Золотого века. София. Артекс. 2018-2020 годы (источник: arteks.bg)

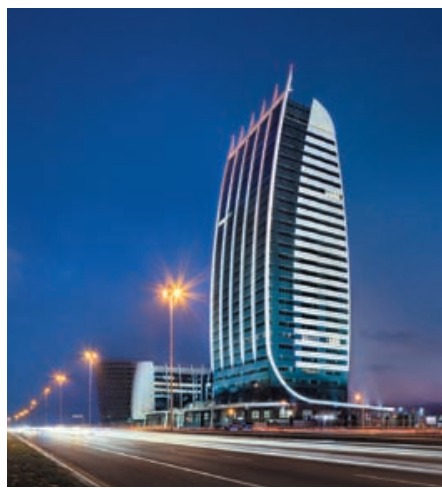

Рис. 3. Офисная башня «Столичный Форт». София. A\&A architects. 2008-2015годы (источник: aаa. bg). Фото А. Эмилова стью и продажами, оказания консультационныхуслуг. В Болгарии зарегистрировано более 32000 таких компаний. Они производят $20 \%$ валового внутреннего продукта нашей страны (около 20 млрд левов), хотя вклад их в этот важный сектор экономики и в развитие архитектурно-строительной отрасли различен.

Зачастую крупные предпринимательские компании, даже имеющие свои собственные проектные отделы, для разработки конкретных проектов привлекают на конкурсной основе лучших болгарских архитекторов. И именно такие объекты стали яркими примерами современной болгарской архитектуры (рис. 1, 2, 3, 4, 5).

Современное болгарское градостроительство развивается в условиях отсутствия планового комплексного подхода, адекватной правовой базы и выраженной децентрализации экономики. В такой ситуации предприниматель становится не только инициатором создания или трансформации материальной среды, то есть архитектуры в широком смысле этого слова, но он же координирует этот процесс и диктует правила его развития.

\section{Картина 30-летия архитектурного процесса}

В этой статье на основе задокументированного, отобранного и проанализированного материала предпринята попытка
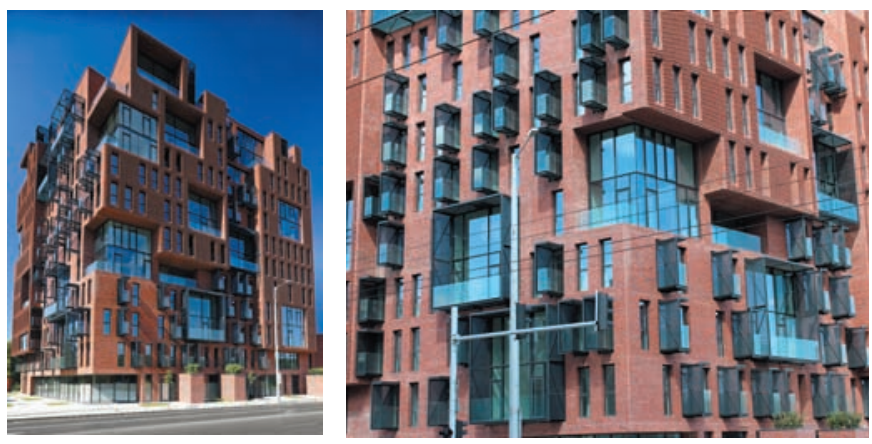

Puc. 4. Red Apple, жилой дом. София. AEDES. 2010-2013 годы. Фото М. Давчевой
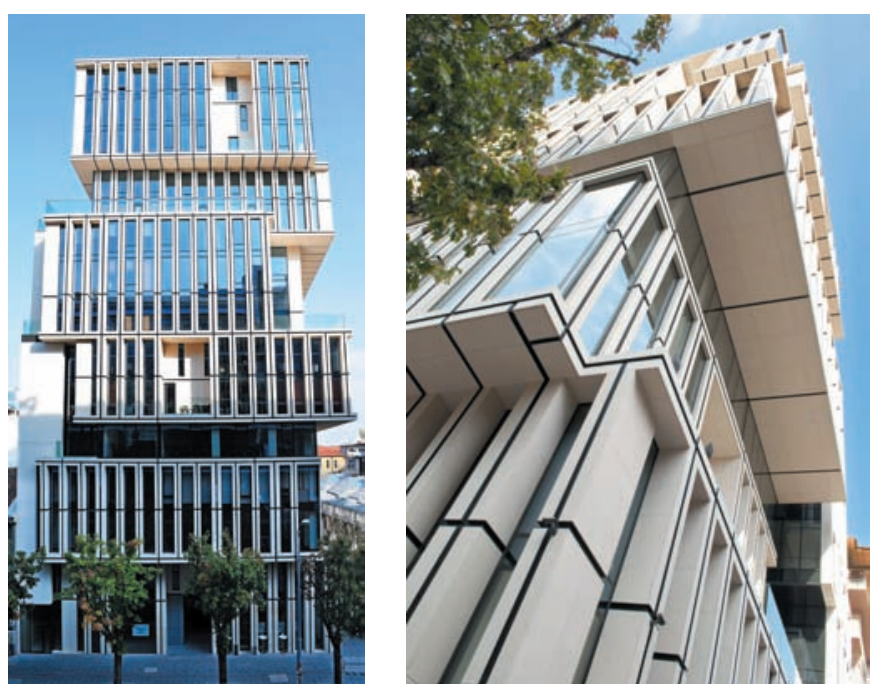

Puc. 5. Городская башня. София. AEDES. 2010-2012 годы. Фото М. Давчевой. 2014 год 
показать панораму болгарской архитектуры за последние тридцать лет (1989-2019) с учётом возможных акцентов в их общей характеристике. Возможно, отсутствие дистанции во времени и литературы по конкретной проблеме являются причиной того, что оценка ситуации, не будет окончательной. Личные наблюдения авторов статьи и результаты успешных национальных конкурсов дают основания надеяться, что нам удалось показать основные процессы, идущие в современной болгарской архитектуре и в том числе влияющие на выбор типа здания. Рассмотрены не только построенные объекты, но и те, которые реализуются в настоящее время.

В статье выделены основные типы зданий, преобладающие в проектировании и строительстве в рассматриваемый период. Такими востребованными жилыми и офисными зданиями, а также гибридной версией - зданиями и комплексами смешанного назначения, потребность в которых постоянно растёт, являются:

- жилые здания, в число которых входят односемейные и многосемейные, многоквартирные дома апартаментного типа, жилые комплексы, отели как временное жилье;

- коммерческие здания и комплексы;

- общественные здания, в том числе офисные и корпоративные здания, банки, многофункциональные сервисные здания и комплексы.

Ответом на разрешение проблем, возникших до 1989 года, стали проекты архитекторов первой волны новой школы, учитывающие пожелания и вкусы инвесторов, принадлежащих к строго определённым социально-финансовым группам нового сообщества специалистов, в процессе объединения нашей страны с миром и, что не менее важно, с возможностью опираться на информацию, материалы и технологии, используемые в настоящее время в разных странах [2].

Появление второй волны связано с двумя важными для болгарской экономики факторами: вступлением страны в Европейский Союз (2007) и мировым экономическим кризисом (2007-2008), отголоски которого и в Европе и, в частности, в Болгарии продолжались до 2009-2010 годов. Характерным для этого периода, как собственно и для всех аналогичных моментов, связанных с критическими событиями в истории, будь то война или экономический кризис, явилось появление множества новых правил, когда, с одной стороны, сохраняются и модернизируются собственные устойчивые модели развития, а с другой - в результате двусторонних интеграционных процессов и глобализации начинается внедрение передовых зарубежныхпрактик и методов.

\section{Типологические трансформации}

В период с 1989-го по 2019 год из постоянно применяемых функциональных типов зданий можно выделить жилые и коммерческие здания. Архитектурный образ этих объектов, их объём, местоположение в застройке и в целом концептуальные решения претерпели наиболее серьёзные изменения.

Изменения других типов зданий - например, офисных проявляются с задержкой в пять-десять лет (до 1995 года - небольшие здания, после 2000-го - крупные здания, и после 2015 года - крупные комплексы). К концу же этого периода отмечаются наиболее серьёзные изменения архитектурных, строительных и управленческих концепций названных типов по сравнению с другими зданиями.

Наиболее полно трансформации (с точки зрения количества и вариантности) подверглись жилые здания. Разнообразие их обусловлено не только различными точками зрения на объёмы и функции жилых структур, но и тем, что всякое жилое здание является продуктом определённого рынка, интересов конкретных социальных групп, финансовых возможностей и ответом на меняющийся быт и стереотипы представлений пользователей (жильцов).

Количество односемейных жилых домов в этот период практически не меняется. Им свойственны большое разнообразие типов, архитектурных решений и стилистических вариаций. Односемейные жилые дома отличаются способностью сохранять свою автономность и даже собственную эстетику.

Для наглядности анализа односемейные жилые дома можно разделить на три типа: иностранная модель богатого дома, интерпретация традиционного болгарского дома, новые модели. Представители недавно сформированного финансово состоятельного слоя предпочитают и зачастую навязывают архитектору для своего дома иностранную модель. Но в большинстве случаев постройки-образцы предназначены для других климатических условий и наследуют иные традиции. Поэтому, когда подобные проекты реализуются автоматически, они далеко не всегда соответствуют ожиданиям заказчика и не находят подержки у широкой общественности.

Одновременно с возведением таких «маленьких дворцов» строят и объекты, определённым образом наследующие типы традиционного болгарского жилища. В таких проектах интерпретируется тип традиционного болгарского дома разных регионов страны: в одних присутствуют эркеры и большие карнизы, в других - каменная кладка первого этажа, характерное покрытие, определённый ритм фасадов... Такие дома хорошо вписываются в природную среду [3].

Особого внимания при рассмотрении типа односемейного дома заслуживает третья модель, представляющая собой результаты многочисленных попыток создать экстравагантный, невиданный, запоминающийся образ нового дома. Вполне естественно, что авторы этих домов - новое поколение архитекторов, сознательно и в полной мере использующих в своих проектах информационные ресурсы и инновационные материалы. Ихпроекты построены на сочетании сложных или простых геометрических форм с чёткой композиционной организацией, выявленной как в интерьере, так и экстерьере дома. Удачные проекты этой модели, будучи реализованы, отличаются оригинальной компоновкой объёмов, умелым использованием материалов и гармоничным взаимодействием с окружающей средой (рис. 6, 7, 8, 9).

Реализации первых проектов многоквартирных жилых домов апартаментного типа (как и проектов односемейных жилых домов) вызвали больше вопросов о характере и успешности 
новой модели жилья, чем ответов, так как в стране отсутствуют подготовленные специалисты - архитекторы и строители, - готовые спроектировать и построить здания такого типа. Мелкий частный предприниматель начинает навязывать своё мнение, а также «сжимать» каждый квадратный метр того, что разрешено законом. Очевидно, что действующее законодательство не может реально регламентировать качество такой застройки и городской среды, когда плотность застройки, её интенсивность, характер, способ и границы, требуемая свободная и зелёная зоны должны быть чётко нормированы [4].

Можно утверждать, что многоквартирные здания, построенные между 1990-ым и 2005-ым годами, удовлетворяли потребность в новой среде обитания представителей среднего класса, которые не могли позволить себе дом на одну семью, но хотели быстро покинуть панельный комплекс, где проживали до этого. Именно это желание - «быстро и любой ценой» и стало одной из причин, по которой предприниматели не дали архитекторам необходимого времени для поиска хороших решений. Как архитекторы, так и строители учились «в процессе», что неизбежно влияло на качество. Архитектура жилых зданий этого периода отличается фасадами, почти всегда решаемыми только с помощью штукатурки (она так и называется: «штукатурная архитектура»), крутыми крышами, большим количеством мансардных окон, угловыми башнями, декоративными деталями и невыразительными силуэтами (хотя и сложной формы) [4].

Среди многофункциональных зданий - жилых и офисных, - построенных до 2000 года, есть примеры создания вырази-

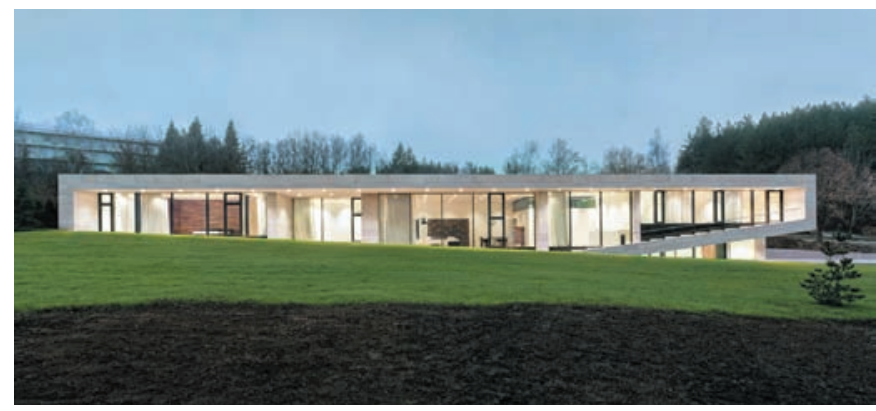

Рис. 6. Жилой дом для одной семьи. Город Тырговиште. 2012-2014 годы. Фото А. Эмилова

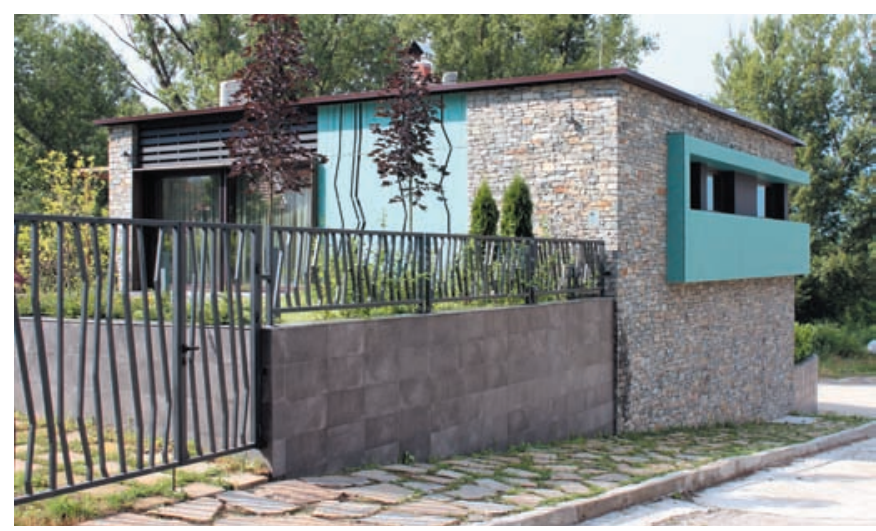

Рис. 7. Жилой дом для одной семьи. Город Балдево. Миодизайн. 2012-2016 годы. Фото М. Давчевой тельного архитектурного облика. Главной идеей авторов было создание общего композиционного решения здания, в котором сочетаются жилые, офисные и коммерческие помещения. В этих зданиях, вызывающих ощущение гармонии, видна чёткая граница между сменой материалов, ритма и растра членений - без резкого, заметного изменения стилистически образа.

Проектирование типа гибридных зданий (с различным соотношением жилых, офисных, коммерческих, гостиничных и т.п. помещений) привело к переосмыслению архитектуры, и, особенно, пониманию неизменности её облика как определяющего фактора в синтетическом образе городской среды. Особое внимание сегодня уделяется общественным пространствам - дворам, помещениям для игр и отдыха и пр. (рис. 10, 11).

В отличие от односемейных и многоквартирных домов жилые комплексы закрытого типа появляются в середине 1990-х и с самого начала отличаются более зрелыми, эстетически обоснованными решениями. Первые два жилых комплекса, возведённые в 1995 году в Софии [жилой комплекс «Бокар»(Bokar) и жилой комплекс «Бакстон» (Buxton), архитектурная мастерская ADA], были восприняты как приятное исключение, которого на рынке комплексного жилья ждали почти десять лет.

Следующие примеры представляют собой спорадические явления в территориальном ареале вокруг Софии и других крупных городов. Данные о проектах и построенных комплексах есть только на период после 2010 года. Все эти постройки - небольшие или грандиозные по размерам, однородные (только односемейные или только многосемейные)

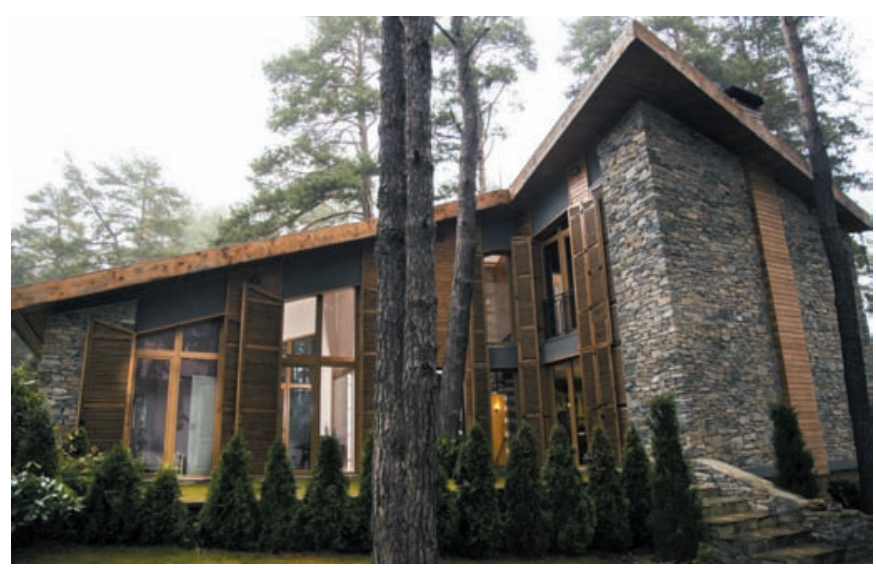

Рис. 8. Жилой дом для одной семьи. Город Батак. Студия VВ. 2010-2011 годы (источник: vbstudio-bg.com)

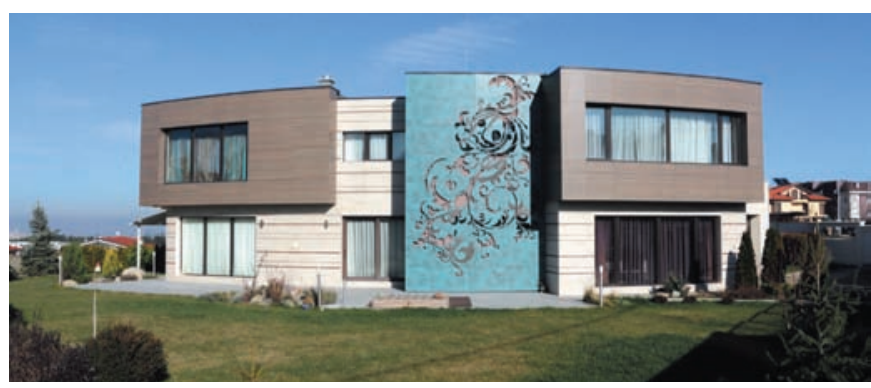

Рис. 9. Жилой дом для одной семьи. София. Миодизайн. 2011-2014 годы. Фото М. Давчевой 
или смешанного типа - имеют современные архитектурные решения, профессионально спроектированный ландшафтный дизайн, территориально близки кестественной природе, профессионально вписаны в окружающую среду.

В более крупныхжилых комплексах серьезное внимание было уделено устройству обслуживающих структур - магазинам, ресторанам, детским площадкам (иногда, в зависимости от величины комплекса были спроектированы детский сад и начальная школа), площадкам для различных видов спорта на открытом воздухе и в помещении (в новых проектах и постройках - помещения для фитнеса, бассейн, SPA, салон красоты и т.д.), организованной парковке для жителей и гостей комплекса, полноценному обслуживанию всех общественных зон (рис. 12, 13).

\section{Гостиницы и гостиничные комплексы}

Тема функциональной специализации отелей является предметом научных и прикладных исследований, особенно после возросшего интереса к ней за последние пятнадцать лет в связи с увеличением потока туристов. В рассматриваемом временном промежутке можно выделить два пиковых периода в развитии отелей, независимо от того, реконструкция это или проектирование нового объекта, отдельное здание или крупномасштабный комплекс. Гостиничная и туристическая индустрия, как неразрывно связанные направления деятельности, становятся важным сектором болгарской экономики.

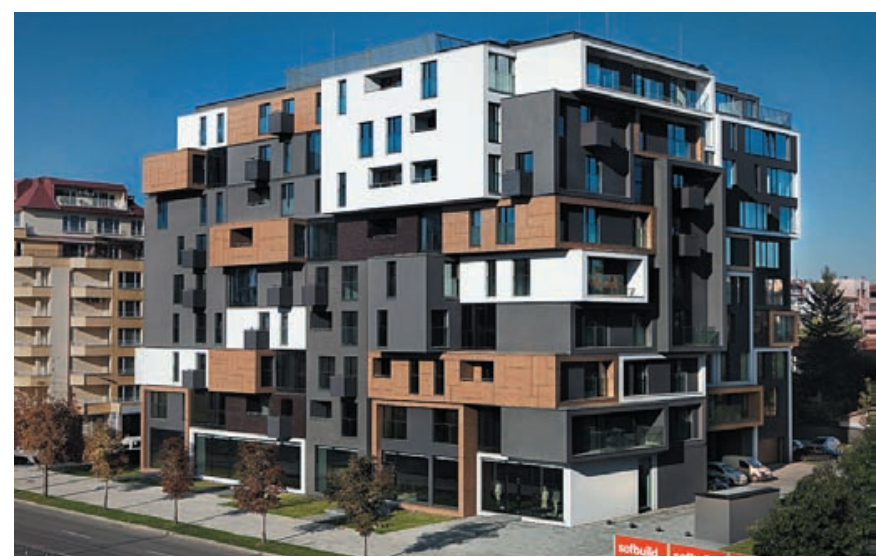

Puc. 10. Многоквартирный жилой дом «Жаклин». София. AEDES. 2006-2008 годы (источник: sofbuild.com)

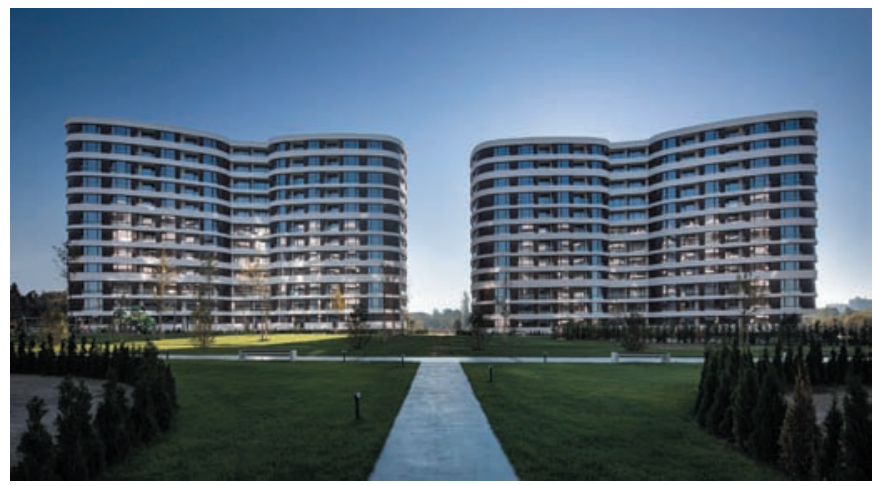

Puc. 11. Многоквартирный жилой дом «Варна Сити Парк». Варна. STARH. 2018-2019 годы (источник: buildingoftheyear.bg)
В городах Болгарии гостиницы начали активно строить В 1950-х и 1970-х годах, а на морских и горных курортах - после 1970-х годов [5]. Эти процессы были обусловлены конкретными политико-экономическими и международными отношениями.

Строительный бум (второй в истории болгарских отелей, но первый за период 1989-2020 годов) в гостиничном бизнесе начался после 2003 года, становясь всё более масштабным на морских и горных курортах. Однако в последние годы можно наблюдать и увеличение числа городских отелей (новых и реконструируемых), ориентированных на бизнес, а также появление новых типов отелей на территории Болгарии [5].

Своего пика этот процесс достигает после 2010 года. Реконструированные, спроектированные и построенные вновь в этот период отели отличаются размерами, продуманностью, наличием в них многих новых функций и услуг, инновационным решением общей концепции, продуманным отношением к окружающей среде, повышенной энергоэффективностью. Это обусловлено возросшими требованиями к материальной базе, обслуживающей все более разнообразные виды туризма, глобализацией процессов в сфере туризма и отдыха, возросшим международным интересом к Болгарии как месту отдыха [6]. С другой стороны, насыщение отеля разнообразными функциями или его специализация с помощью определённых функций (море, лыжи, спа, изысканная кухня, вино, бизнес и т.д.) позволяет обеспечить круглогодичное функционирование отеля, несмотря

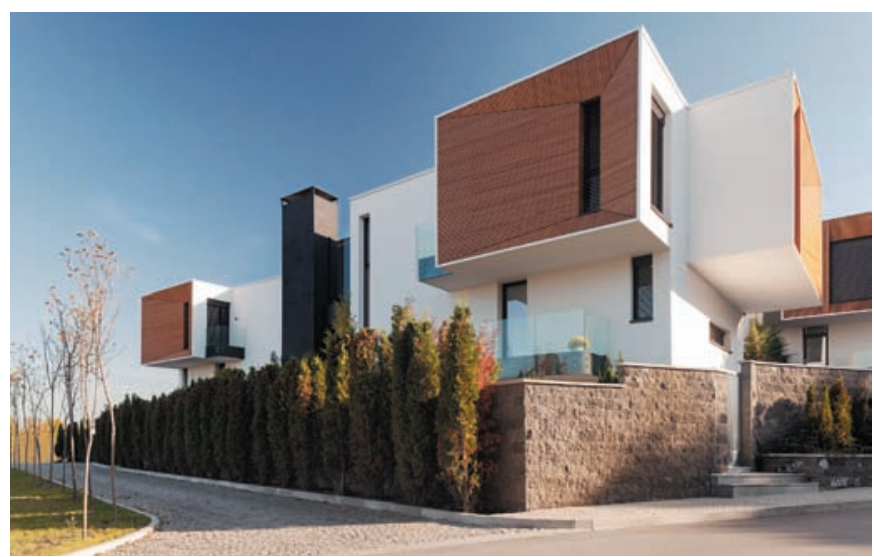

Рис. 12. Жилой комплекс «Джентел Хаус Резиденс». София. LPархитекторы. 2017-2020 годы (источник: buildingoftheyear.bg)

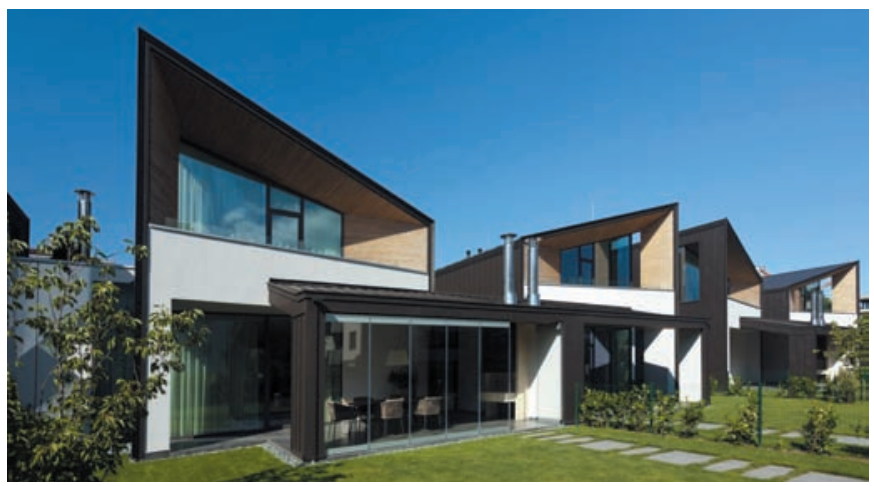

Рис. 13. Жилой комплекс «Манастирски Ливади». София. LPархитекторы. 2013-2014годы (источник: buildingoftheyear.bg) 
на то, что климат Болгарии отличается чёткой сменой времён года, в связи с чем некоторые из ключевых отелей до сих пор были сезонными. Конечно, для городских отелей и комплексов, имеющих удобное расположение, этот вопрос решается легко.

Как и другие типы современных зданий, отели могут быть сгруппированы в зависимости от объёма (количество спальных мест), расположения (морские, горные, городские, внегородские и т.п.), назначения (типы услуг профилируются или, наоборот, наличие многофункциональной базы для различных мероприятий). Отели, как и жилые здания, можно систематизировать по трём основным видам: адаптированная зарубежная модель (мировые гостиничные бренды выходят на болгарский рынок не только со своими требованиями, но и со стандартными функциональными схемами и определёнными архитектурными образцами); модель, отражающая местные условия с целью поиска идентичности (территориальная идентичность, когда источником вдохновения выступает окружающая среда, или историческая идентичность, когда при формировании образа используют ссылки на болгарскую традиционную архитектуру); инновационные модели, в основе которых лежат инновационные архитектурные концепции [7]. Эти концепции являются продуктом поисков на основе новых требований и ожиданий сегодняшнего потребителя. Результат достигается с помощью современных технологий и материалов. Проекты отелей инновационной модели в

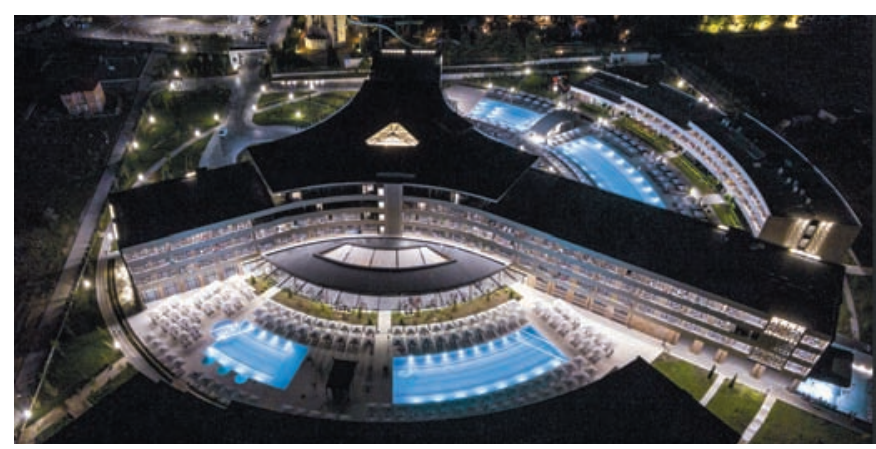

Pис. 14. Гостиничный комплекс «Аквапарадайз Ресорт». Город Несебр. Миодизайн. 2012-2018 годы. Фото Н. Динова

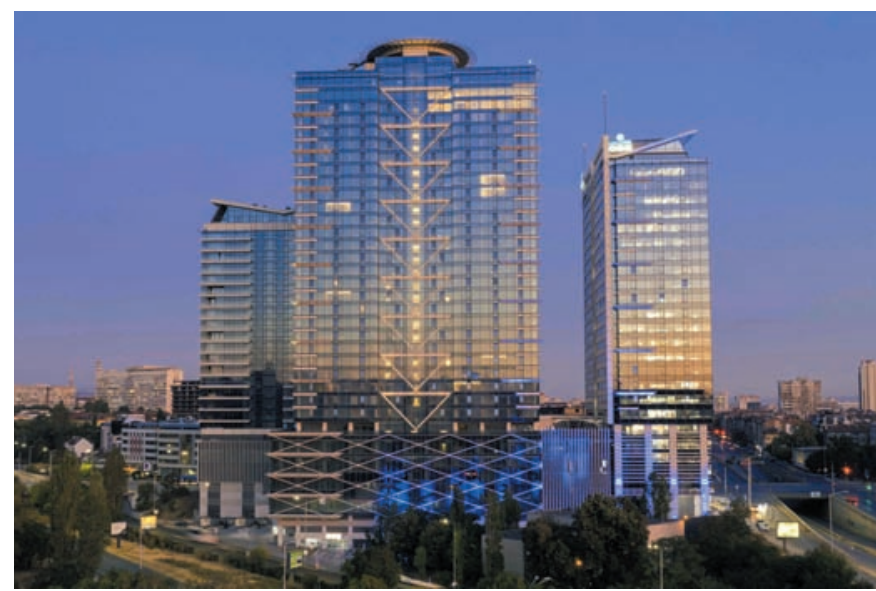

Рис. 15. Гранд-отель «Милениум». София. НИКМИ. 2015-2020 годы (источник: gradat.bg) большинстве случаев отличает узнаваемый авторский почерк архитектора (рис. 14, 15, 16, 17).

\section{Коммерческие здания}

В рассматриваемый период (1989-2019) архитектурный облик коммерческих зданий меняется наиболее заметно. Изменения касаются объёмов построек, эстетики архитектурных решений, средств достижения выразительности. Возрождаются «забытые форматы» (крупные многофункциональные торговые центры), а также импортируются унифицированные концепции мировых брендов. В то же время формируются местные модели с индивидуальной архитектурой в соответствии с запросами клиентов, местом строительства, типами товаров и т.д. (рис. 18, 19).

Безусловно, наиболее впечатляющими с точки зрения масштаба, инвестиций и количества профессионалов, занятых в проектировании, строительстве, эксплуатации и управлении, являются крупные торговые образования, так называемые «моллы». И хотя в каждом болгарском городском центре второй половины XX века [8] есть крупные торговые центры - Центральный универсальный магазин (ЦУМ. София, 1965), городские и районные универмаги (ГУМ и РУМ) после перемен, начавшихся в 1989 году, они невостребованны. Это обьясняется отсутствием интереса и (или) финансовых возможностей у индививидуального частного предпринимателя, с одной стороны, и отсутствием государственных/муниципальных правовых

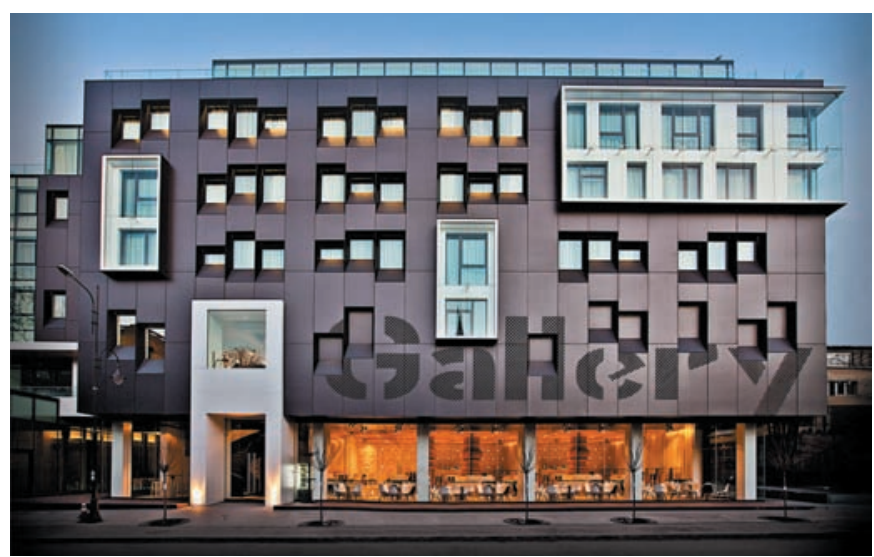

Рис. 16. Арт-отель «Галерея Граффити». Варна. Archis. 2009-2011 годы (источник: buildingoftheyear.bg)

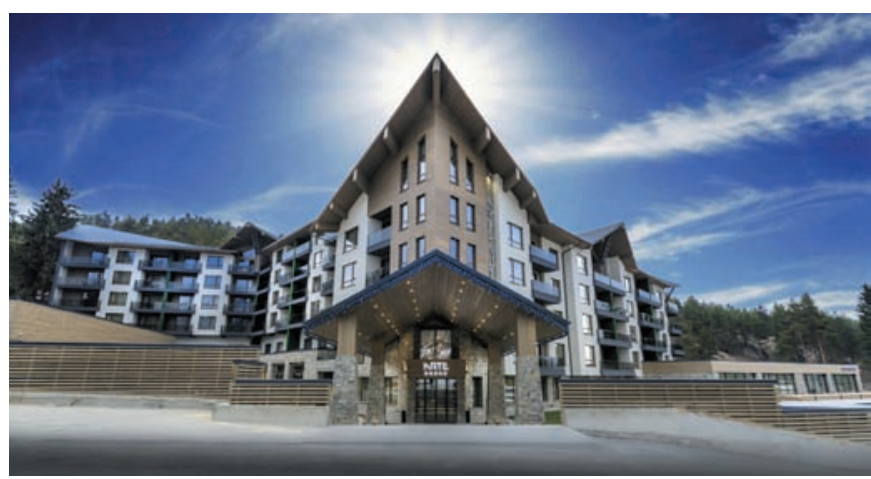

Рис. 17. Арт-отель. Город Велинград. РТ-Консульт. 20142017 годы (источник: buildingoftheyear.bg) 
норм, обеспечивающихуправление финансово-экономическими и эксплуатационными процессами, с другой.

С открытием в Софии трёх новых торговых центров - «Парк Центр Софиа», «Молл оф Софиа», «Скай Сити Софиа» (Park Center Sofia, Mall of Sofia, Sky City Sofia) - в течение 2006 года всю страну охватила лавина проектирования и строительства аналогичных объектов. Вопросом престижа и моды стало сооружение хотя бы одного торгового центра в каждом крупном болгарском городе. Создание центров стали рассматривать как актуальную проблему, её всесторонне, активно обсуждали в СМИ эксперты в области архитектуры, техники, экономики, социологии, недвижимости, журналисты и рядовые граждане [9].

Интенсивность этой деятельности в период 2006-2013 годов привела к накоплению и повторению ошибок в функционально-технологическом решении проектируемых зданий, учёте их связей с окружением, построением коммуникаций. Отсутствие опыта стало причиной внедрения в качестве базовых двух моделей торговых центров.

Первая модель характеризуется применением схемы: «пространство атриума - галерея», что, в свою очередь, уменьшало количество вариантов решений при использовании подобной компоновки пространств. Вторая модель, использующаяся при строительстве торговых центров, - это создание уменьшенных копий знаменитых, понравившихся иностранных объектов или копирование авторского произведения болгарского архитектора, что также не способствовало достижению значимых результатов (рис. 20, 21).

\section{Офисные здания}

Офисные здания представляют собой динамично развивающийся тип. Процесс активизации офисного строительства начался после 1995 года с использования для нужд первых частных предпринимателей небольших по площади помещений в существующих зданиях. Первые офисные помещения - это банковские филиалы и офисы различного назначения (юридические, бухгалтерские, дизайнерские и др.). Примерно через пять лет в ключевых местах городской застройки появляются отдельные самостоятельные корпоративные здания, принадлежащие банкам и другим акционерным компаниям. Зачастую проектирование этих зданий становится своего рода экспериментальной архитектурной лабораторией объёмно-пространственного формирования с применением смелых конструктивных решений и новейших строительных и отделочных материалов (рис. 22, 23, 24, 25).

С момента своего появления и до сегодняшнего дня офисные здания как архитектурный тип сохраняют устойчивую тенденцию к росту и прошли два пиковых периода реализации. Первый пик был зафиксирован в период с 2000 года до завершения финансово-экономического кризиса в Болгарии (2008-2010). Здания, построенные в этот период, вполне сопоставимы с лучшими зарубежными аналогами, обладают выраженными индивидуальными чертами. При их строительстве использованы самые современные материалы. Следующий пик, начавшийся в 2015 году, продолжается по настоящее время. В условиях финансового кризиса появился необходимый временной ресурс для исследования, обоснования и

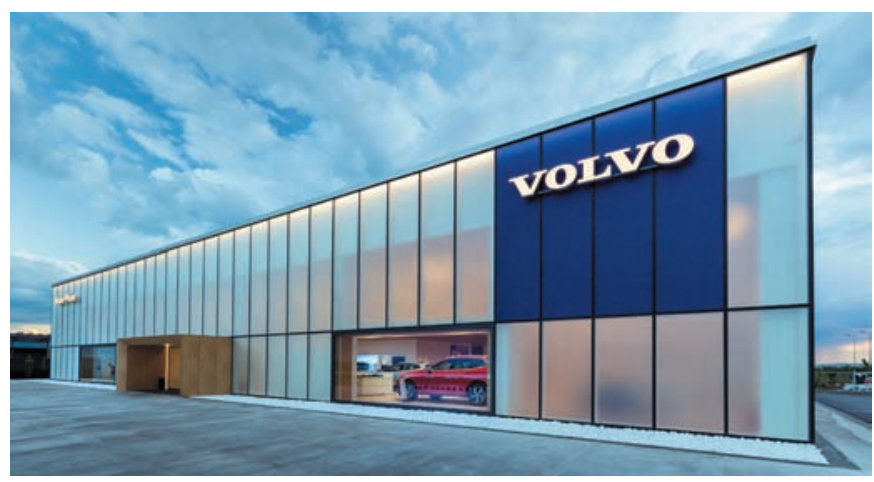

Рис. 18. Выставочный зал «Вольво». София. Archico. 20182019 годы (источник: dibla.com)

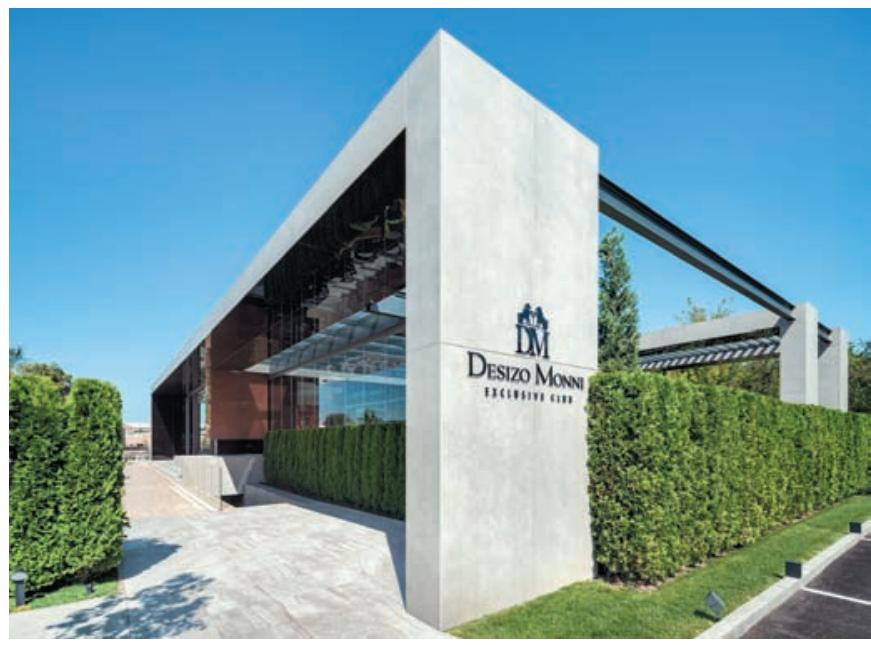

Рис. 19. Многофункциональное здание «Десизо Монни». Плевен. A\&A architects. 2016-2018 годы (источник: aaa.bg)

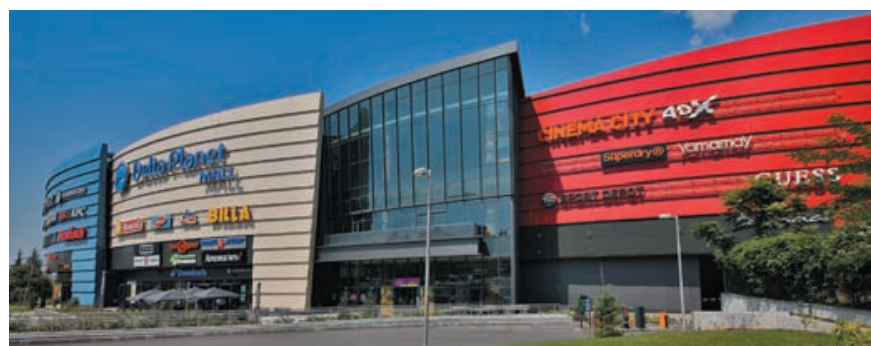

Рuс. 20. Торговый чентр «Дельта Планет». Варна. 20102018 годы (источник: buildingoftheyear.bg)

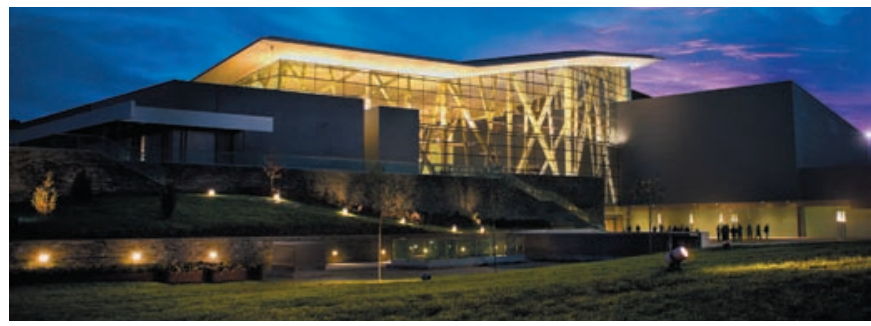

Рис. 21. Молл Ринг. София. Skica Studio. 2011-2014 годы (источник: buildingoftheyear.bg) 
разработки эффективной бизнес-модели офисных центров. Это обусловило большую эстетическую привлекательность, осмысленность и устойчивость многофункциональной модели. Как и в случае с жилыми домами, после 2010 года многофункциональные крупномасштабные офисные комплексы возводятся парллельно с отдельностоящими зданиями.

Эти здания, обладающие высокими эстетическими и энергоэффективными качествами, ставят болгарскую архитектуру в один ряд с передовой международной практикой. Примечательно, что офисные мегаструктуры в большинстве случаев являются инвестиционными проектами болгарских корпораций,- и их комплексность обеспечит гармоничность и ансамблевость застройки в долгосрочной перспективе. Многофункциональные комплексы вместе с небольшими офисными зданиями становятся формирующим фактором современной городской среды, зачастую символом определённого места, подчёркивая его индивидуальность и создавая предпосылки для повышения качества жизни в окружающем районе.

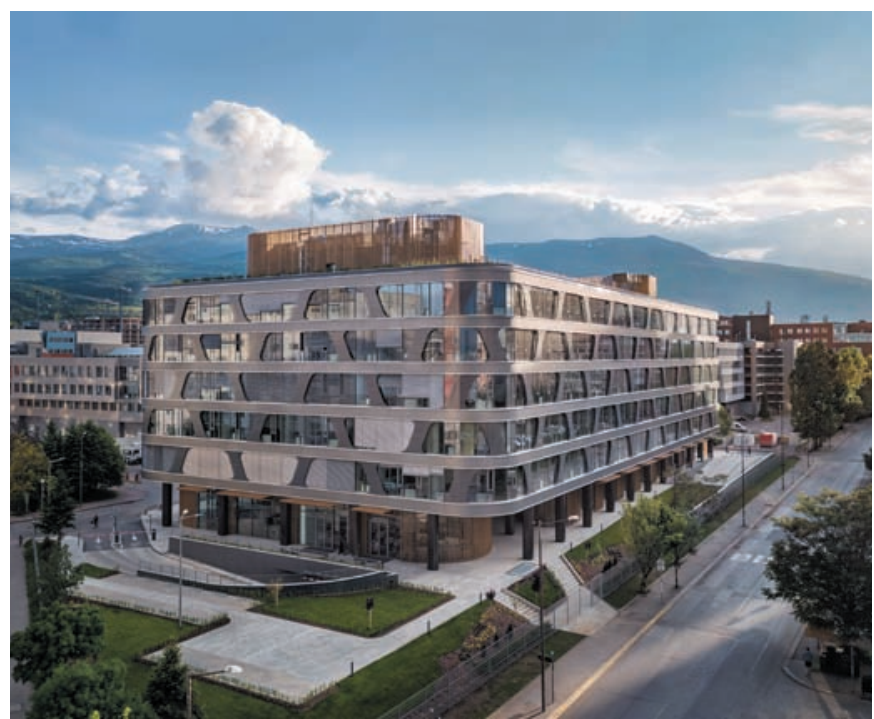

Puc. 22. Офисное здание «Бизнес-Парк». София. A\&A architects. 2017-2019 годы (источник: aaa.bg)

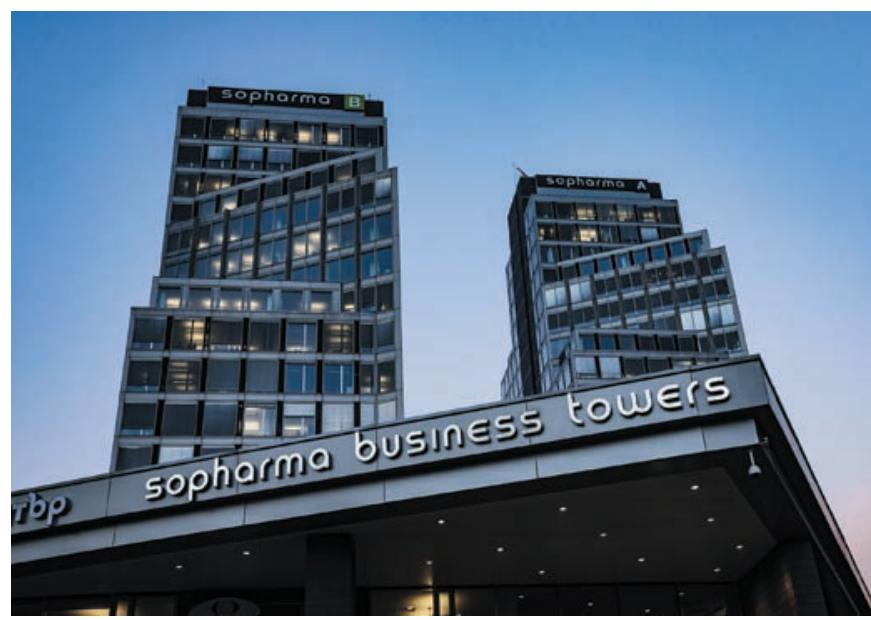

Pис. 23. Многофункциональный комплекс «Софарма Бизнес Тауер». Архитектоника. 2009-2011 годы (источник: buildingoftheyear.bg)
***

Рассмотренные в данной статье процессы в современной болгарской аритектуре нельзя считать прямым следствием социально-экономических и политических событий в Болгарии.

Динамика движения современной архитектуры прошедших тридцати лет имеет свой исторический ритм. Их начало определяется современной историей каждой страны Восточной Европы [10]. Еще в конце 1980-х - начале 1990-х годов архитекторы и представители обществености отмечали отсутствие эволюционного развития, обусловленное «искусственно навязанной изоляцией» от глобальных мировых процессов. Тенденции развития новой болгарской архитектуры типичны для каждого нового исторического периода, отмеченного значительными реформами.

Характерной, возможно, даже отличительной чертой Болгарии является быстрое (сразу после 1989 года - после окончания первого этапа реформ) перераспределение прав собственности на крупные производственные, торговые предприятия, предприятия

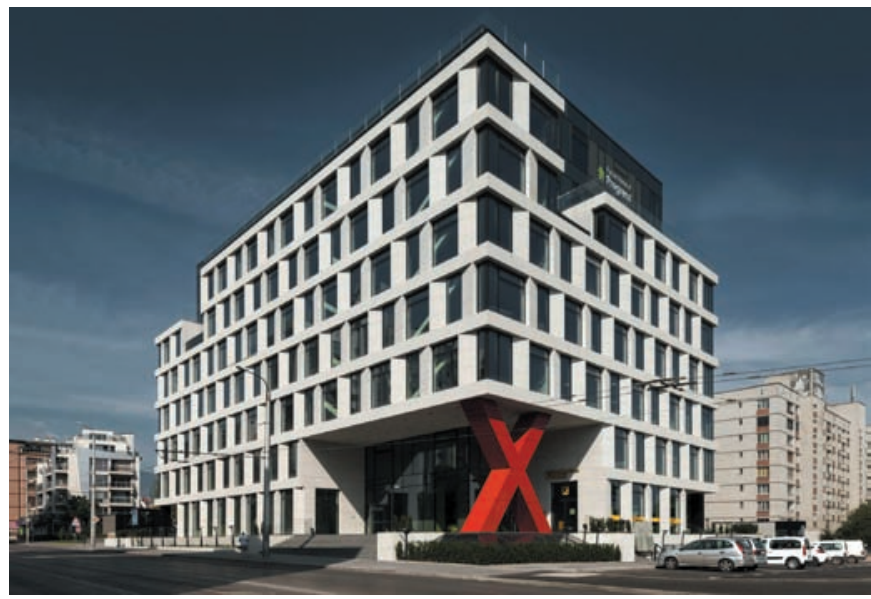

Pис. 24. Многофункциональное здание «Графикс». София. LPархитекторы. 2012-2014годы (источник: buildingoftheyear.bg)

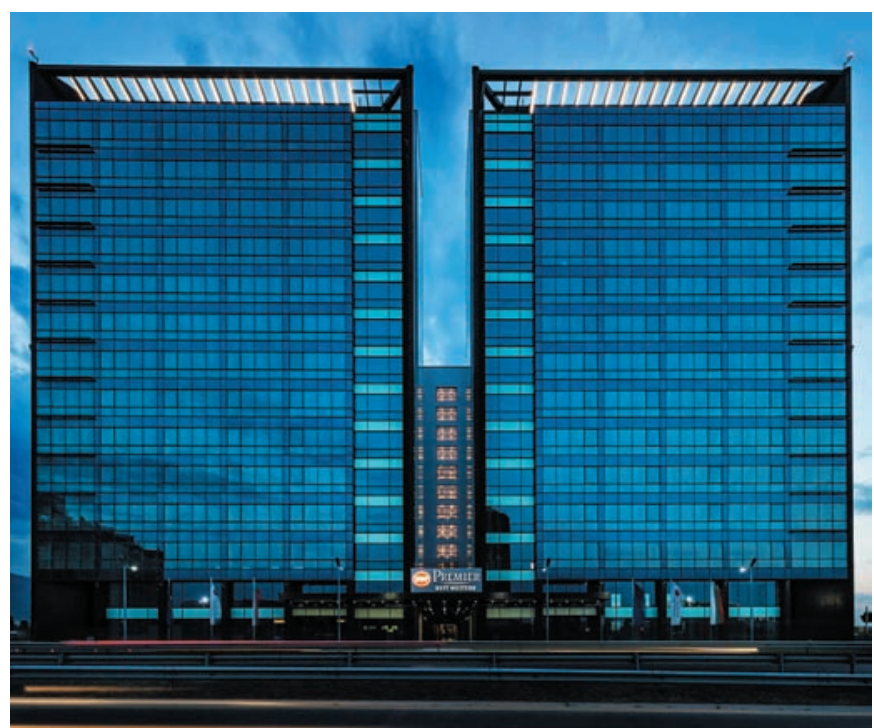

PUс. 25. Офисное здание «BLE Office». София. ASA. 2014-2016 годы (источник: buildingoftheyear.bg) 
сферы услуг и связи. Реституция стала причиной дальнейшего перераспределенния прав собственности на ключевые объекты, и всё это, в свою очередь, привело к быстрому формированию частных структур, которые получили право распоряжаться капиталом и, соответственно, инвестировать в окружающую материальную и нематериальную среду по своему усмотрению [11]. Естественно, что первые инвестиции были направлены на разрешение самых насущных проблем - строительство жилья, улучшение среды обитания, децентрализацию производства, торговли и обслуживания. Развитие городов, реконструкция городских центров, строительство транспортных и коммуникационных систем - результат следующего периода (после 2007-2008 годов), когда стало возможным утверждать, что существуют объективная необходимость и условия для внешнего финансирования (крупные иностранные компании, поддерживающие страны - члены ЕС - целевыми инвестициями и через европроекты).

К сожалению, в течение первого десятилетия рассматриемого периода (1989-2000) у специалистов (включая архитекторов), вовлечённых в создание облика Новой Болгарии, превалировало желание абстрагироваться от событий, практики и опыта прошлых десятилетий. Они пытались решить вновь появившиеся проблемы, ответить на вновь возникшие вопросы, не имея собственного необходимого опыта и не опираясь на анализ иностранного, исключая преемственность. Это неизбежно привело к большому количеству неудачных проектов и построек, но возникшая критическая и аналитическая реакция общества обусловила необходимость использования в дальнейшем всего арсенала инструментов: качественные зарубежные аналоги, опыт собственного недавнего прошлого, привлечение высококвалифицированных кадров, обладающих индивидуальным творческим почерком.

В данной статье мы уже упоминали одну из проблем болгарской архитектуры рассмотренного тридцатилетия - отсутствие правовой и нормативной основы - в целом, и законов, касающихся городского планирования и архитектурного развития, в частности. Имеющаяся нормативно-правовая база явно не соответствовала и была непригодна для регулирования недавно сформировавшейся экономической и предпринимательской деятельности, не обеспечивала установление ориентиров развития архитектурного творчества. Разрешение этой ситуации требовало и до сих пор ещё требует внесения изменений и дополнений в нормативную базу: сегодня ещё нельзя сказать, что она работает рационально, а инвестиционные процессы в экономике, со своей стороны, поставили вопрос о разумном сроке одобрения проектов в соответствующих учреждениях.

В целом, проблемы, с которыми сталкиваются проектные организации, архитектурные бюро и мастерские, можно разделить на пять групп:

1) трудности, связанные с процессом разделения собствености на частную (в том числе вопросы реституции), муниципальную и государственную;

2) отсутствие во многих случаях инфраструктуры вообще или её устаревание;
3) отсутствие современного модернизированного кадастра, полно отражающего имущественные вопросы (собственость) инфраструктуры и собственно здания;

4) отсутствие модернизованной удобной и эффективной процедуры разработки и вступления в силу новых территориально-пространственных и градостроительных планов [Общий градостроительный план (Генеральный план); Планы детальной планировки];

5) отсутствие налаженных отношений между отдельными участниками строительного процесса и др.

До середины рассматриваемого периода причиной публичной критики нового строительства были безликость, отсутствие разнообразия, низкое качество строительства, уничтожение объектов архитектурного наследия, низкий уровень эстетики, плохой микроклимат и т.д.

Начиная с 2010 года накопленный опыт и учёт вышеперечисленных факторов привели к видимым качественным результатам как в процессе проектирования и строительства рассмотренных типов зданий, так и для архитектурного облика городской застройки в целом. Благодаря недавно сформированным группам и форумам (проходящий ежегодно в Болгарии архитектурный фестиваль «0ne Architecture week», инициативные действия Ассоциаций Трансформаторов, НеФормальные, Группы «ГОРОД», Визия для Софии и т.д.) к решению проблем современного города привлечены не только специалисты, но и активные граждане.

В большинстве случаев именно эти отношения сотрудничества, обрели в последнее время устойчивый формат и всё больше определяют современную ситуацию в болгарской архитектуре. Разнообразие подходов к решению проблем, появление новых типов зданий и развитие архитектурных процессов синхронно с мировыми архитектурными тенденциями стали фундаментальными факторами, которые не только вывели болгарскую архитектуру на международную арену, но и позволяют создавать новые объекты в гармоничной связи со сложившейся архитектурно-градостроительной средой, наследуя её индивидуальность и наделяя чертами новой идентичности.

\section{Лuтература}

1. Ташева, С. Идеология и архитектура / С. Ташева // Българският XX век в изкуствата и културата. - София : ИИИзк, БАН, 2019. - С. 334-341. ISBN: 978-954-8594-76-9

2. Давчев 0. Дигитална трансформация на интериорния проект / О. Давчев. - София : Direct Services, 2019. ISBN 978619-7171-81-5

3. Стефанов, С. Еднофамилни и двуфамилни жилищни сгради / С. Стефанов. - София : Техника, 1989. ISBN 954-03-0551-9

4. Матеев, Матей. Кръгла маса по проблемите на жилищната архитектура / М. Матвеев // Архитектура. - 1995. - № 3. - С. 31-35. ISSN 0324-1254

5. Ковачев, А. Градоустройство. Част 1. Основи на теорията и практиката на градоустройството / А. Ковачев. - София : Пенсофт, 2003. - С. 269-295. ISBN 954-642-9 
6. Грозев, 0. Интерпретиране на архитектурната традиция в съвременните хотели / О. Грозев. - София : Сезам-ВР, 2015.

7. Davcheva, M. Avant-garde trends in architecture of hotel prototype in XXI century / M. Davcheva, 0. Davchev // Proceedings of the XV international scientific conference, vol.3. - Sofia, 2015. - P.100-111. ISSN 1314-071

8. Давчева, М. Съвременните търговски сгради в България 1990-2010 г. / М. Давчева. - София : Академично издателство „Професор Марин Дринов“, БАН, 2013. ISBN: 978-954-322-590-3

9. Семерджиева, И. Предимства, недостатъци и бъдещо развитие на търговските сгради / И. Семерджиева // Архитектура. - 2011. - № 4. С. 46-50. ISSN 0324-1254

10. Ташева, С. Новият човек и новият град: отражения / C. Ташева // Българският XX век в изкуствата и културата - София : ИИИзк БАН - 2019. - С. 344-348. ISBN: 978-954-8594-76-9

11. Ташева, С. Архитектурата на прехода / С. Ташева // Българският XX век в изкуствата и културата - София : ИИИзк БАН - 2019. - С. 608-618. ISBN: 978-954-8594-76-9

\section{References}

1. Tasheva, S. Ideologia i arhitektura [Ideology and architecture]. In Balgarskiyat XX vek $v$ izkustvata $\mathrm{i}$ kulturata [The Bulgarian XX century in arts and culture]. Sofia, IIIzk, BAN Publ., 2019, pp. 334-341. ISBN: 978-954-8594-76-9

2. Davchev 0. Digitalna transformatsia na interiornia proekt [Digital transformation of the interior design]. Sofia, Direct Services Publ., 2019. ISBN 978-619-7171-81-5

3. Stefanov S. Ednofamilni i dvufamilni zhilishtni sgradi [Single-family and two-family residential buildings]. Sofia, Tehnika Publ.,1989. ISBN 954-03-0551-9

4. Mateev Matey. Kragla masa po problemite na zhilishtnata arhitektura [Round table on the problems of residential architecture]. Arhitektura [Architecture], 1995, no. 3, pp. 31-35. ISSN 0324-1254

5. Kovachev A. Gradoustroystvo. Chast 1. Osnovi na teoriyata i praktikata na gradoustroystvoto [Urban planning. Part 1. Fundamentals of the theory and practice of urban planning]. Sofia, Pensoft Publ., 2003, pp. 269-295. ISBN 954-642-9

6. Grozev 0. Interpretirane na arhitekturnata traditsia $\checkmark$ savremennite hoteli [Interpretation of the architectural tradition in modern hotels]. Sofia, Sezam-VR Publ., 2015.

7. Davcheva M., Davchev 0. Avant-garde trends in architecture of hotel prototype in XXI century. Proceedings of the XV international scientific conference, vol.3. Sofia, 2015, pp. 100-111. ISSN 1314-071

8. Davcheva M. Savremennite targovski sgradi v Bulgaria 1990-2010 g. [Contemporary commercial buildings in Bulgaria 1990-2010]. Sofia Akademichno izdatelstvo „Profesor Marin Drinov“, BAN Publ.,. 2013. ISBN: 978-954-322-590-3

9. Semerdzhieva I. Predimstva, nedostatatsi i badeshto razvitie na targovskite sgradi [Advantages, disadvantages and future development of commercial buildings]. Arhitektura [Architecture], 2011, no. 4, pp. 46-50. ISSN 0324-1254.

10. Tasheva S. Noviyat chovek i noviyat grad: otrazhenia [The new man and the new city: reflections]. In Balgarskiyat $X X$ vek $v$ izkustvata $i$ kulturata [The Bulgarian XX century in arts and culture]. Sofia, IIIzk BAN Publ., 2019, pp. 334-341. ISBN: 978-954-8594-76-9

11. Tasheva S. Arhitekturata na prehoda [The architecture of the transition]. In Balgarskiyat XX vek vizkustvata $i$ kulturata [The Bulgarian XX century in arts and culture]. Sofia, IIIzk BAN Publ., 2019, pp. 608-618. ISBN: 978-954-8594-76-9

Ковачев Атанас Димитров (София-Варна, Болгария). Член-корреспондент Болгарской академии наук, доктор архитектуры, профессор градостроительства, иностранный член РААСН. Руководитель кафедры «Архитектура и урбанистика» Варненского свободного университета им. Черноризца Храбра, руководитель департамента «Инфраструктурные проекты» Лесотехнического университета (Болгария, 1797, София, бульв. Климента Охридского, 10), почётный профессор Московского архитектурного института (государственной академии), руководитель архитектурной мастерской «Ковачев архитекти - Е00Д». Эл.почта: atanas_kovachev@mail.bg.

Мария Давчева (София, Болгария). Кандидат архитектуры, доцент. Архитектор Болгарской академии наук (Болгария, 1040, София, ул. 15 ноября, 1). Совладелец архитектурного бюро «Miodesign». Эл. почта: miodesign@abv.bg.

Kovachev Atanas D. (Sofia - Varna, Bulgaria). Corresponding member of the Bulgarian Academy of Sciences, Doctor of Architecture, Professor of Urban Planning, Foreign Member of RAACS. Head of the Department of Architecture and Urban Studies, at Varna Free University named after Chernorizets Hrabar, Head of the Department of Infrastructure Projects at the Forestry University (Bulgaria, 1797 Sofia, 10 Kl. Ohridski Boul.), Honorary Professor of the Moscow Architectural Institute (State Academy), Head of the Architectural Studio "Kovachev Architects - E00D". E-mail: atanas_kovachev@mail.bg.

Maria Davcheva (Sofia, Bulgaria). Candidate of Architectural Sciences, Associate Professor. Architect of the Bulgarian Academy of Sciences. (Bulgaria, Sofia, 1040, 1, "15 Novemvri" str. BAS), co-owner of the architectural bureau Miodesign. E-mail: miodesign@abv.bg. 